\title{
Waste Reduction on Personality Action System of Daily/Piece-rated Process
}

\author{
Benedictus Rahardjo \\ Department of Industrial Engineering, Petra Christian University, Surabaya, Indonesia \\ beniepetra.ac.id
}

\begin{abstract}
PT. X is a multinational company that works in the consumer goods sector. PT. X has many departments and one of them is the Human Resources (HR) Department whose role is to maintain all of the employees under PT. X. The HR Department also has some subfunctions. One of them is HR Services. Employees that work with PT. X are divided into two categories: monthly employees and daily/piece-rated employees. One of the processes that HR Services provides for the daily/piece-rated employees is ePAF daily/piece-rated, which can be monitored by a verification process. If an ePAF is not verified, then it is possible for the ePAF process to be denied and that is a waste that can cause over-processing for HR Services. There were 750 ePAF denials in 2016 with an average processing time of 1.78 hours needed to resubmit each process. An analysis was done using a Pareto Chart and Fishbone Diagram to reduce the time wasted and to look for countermeasures for each of the root causes. The Pareto Chart shows three major problems occurring. These are: errors in the closing date, errors in the transaction date, and errors in the supporting document. The root causes of the problem come from human error, method errors, and system classification errors. The solutions proposed are expected to reduce the numbers of ePAF denials by around $51.2 \%$.
\end{abstract}

Keywords: Waste, Over Processing, Fishbone Diagram, Improvement, Man-Hour Savings.

\section{Introduction}

PT. X has several departments in operation in their business and one of them is the Human Resources (HR) department. The HR department has several functions. One of these functions is to maintain the services given to the employees, and this function is mantained by the HR Services department. There are specific teams to handle more specific things and one of them is Compensation and Benefit (C\&B). HR Services also has a sub-function based on their tasks and that is $C \& B$ Admin and C\&B Specialist.

There are 2 types of employees that work in PT. X based on their payment period. These are monthly employees and daily/piece-rated employees. PT. X uses ePAF (Electronic Personal Action Form) system to maintain and record every personnel action of the daily/piece-rated employees that impacts the company. This particular process is called the ePAF daily/piecerated process.

HR Services aim to make their process faster to reduce man-hours needed and to provide their services in a timely manner. In the current condition there is much wastefulness that occurs within the ePAF daily/piece-rated process and can be improved in order to reduce man-hours needed. There are also other special instances that cause unnecessary wastefulness. The aim of this research is to reduce the man-hour usage in the ePAF daily/piece-rated process and improve its efficiency.

\section{Methods}

Every process that exists in ePAF daily/piece-rated will be observed in an effort to look for waste in the process. Waste in Japanese is known as "muda" and every type of activity or processes that does not give any added value to the product but increases the time and cost needed fits into this category. Taiichi Ohno, in Lean Manufacturing [1], lists seven wastes and developed a tool to categorize waste. The seven wastes are: overproduction, transportation, inventory, defects, waiting, over-processing, and motion.

There are many discussions about waste reduction. Seth and Gupta [2] succeeded in applying value stream mapping for lean operations and cycle time reduction in an Indian case study. Models for both Lean and Green systems were introduced by Bergmiller and McCright [3]. This model includes management systems, waste identification, and implementation of waste reducing techniques (WRT) to achieve desired business results. Verenich et al. [4] discussed minimizing over-processed waste in business processes via predictive activity ordering. Experiments on two real-life processes show that these predictive machine learning models outperform traditional methods while incurring minimal runtime.

\subsection{DMAIC (Define, Measure, Analyze, Improve, Control)}

Define, Measure, Analysis, Improve, Control (DMAIC) are five well-structured stages of the improvement process that are used to improve the quality of the process and are usually related to six sigma activities [5]. DMAIC is usually used to 


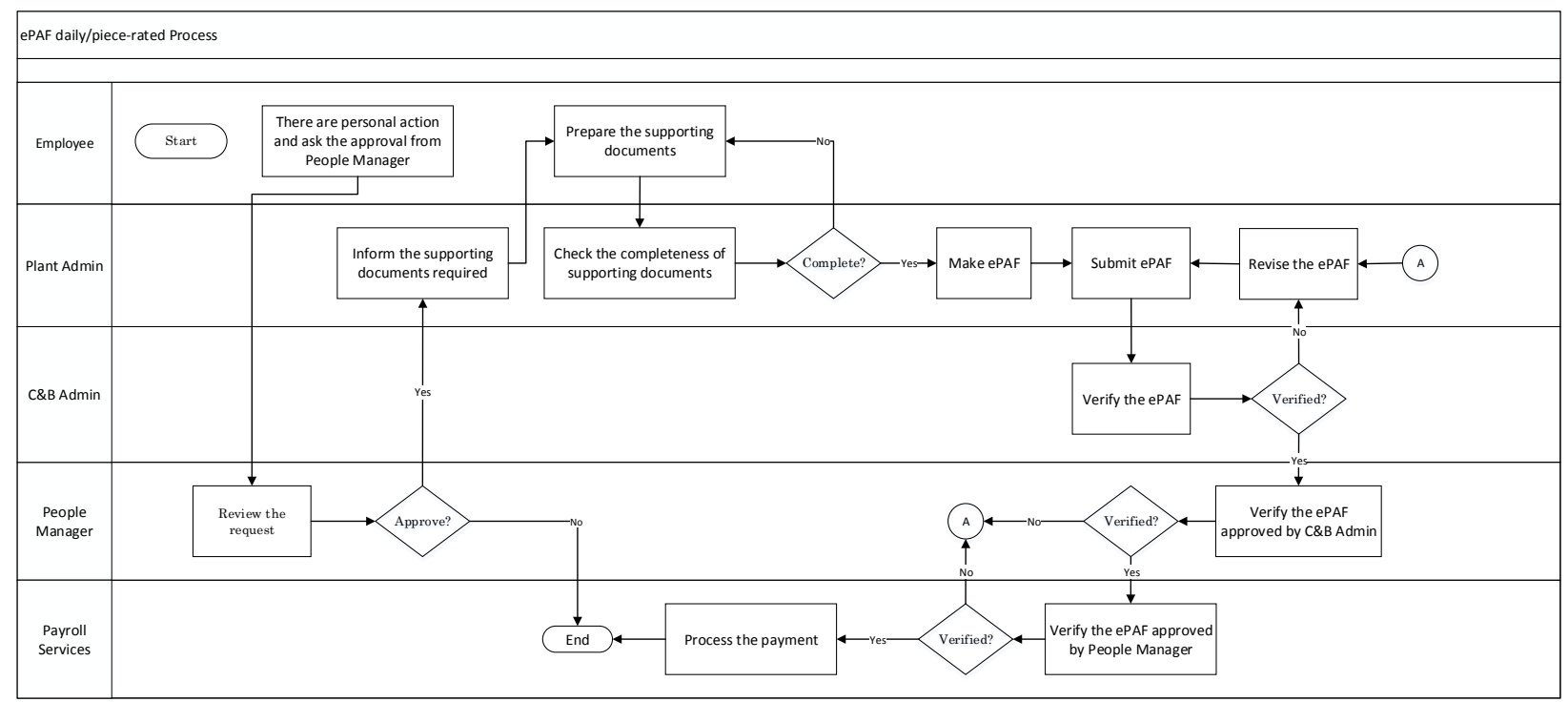

Figure 1. Stages of ePAF daily/piece-rated process

implement the solution designed to solve the root causes and make a control plan so the problem will not occur again in the future. A tool that is frequently used in the measure stage is the Pareto Chart. This chart combines two graphs, a bar and a line to show the frequency of the occurrence in descending order [6].

\subsection{Impact Effort Matrix}

The impact effort matrix is a simple tool purposed to generate a priority in choosing several options with limited resources [7]. Analysis uses the impact effort matrix to consider effort needed for each proposed improvement and impact given by each idea, project, etc.

\section{Result and Discussion}

EPAF daily/piece-rated process in PT. $\mathrm{X}$ is closed every week, and the end process is handled by the Payroll Services Department. All ePAFs that are made have to follow the calendar determined by Payroll Services. Figure 1 shows stages of the ePAF daily/piece-rated process.

There are five parties involved in the process, as seen in Figure 1. They are: Employee, Plant Admin, HR Services Admin (C\&B Admin), People Manager, and Payroll Services. The employee is a daily/piece-rated worker that works for PT. X. Plant Admin is someone who is chosen by their department to handle and record all transactions submitted by the employees. People

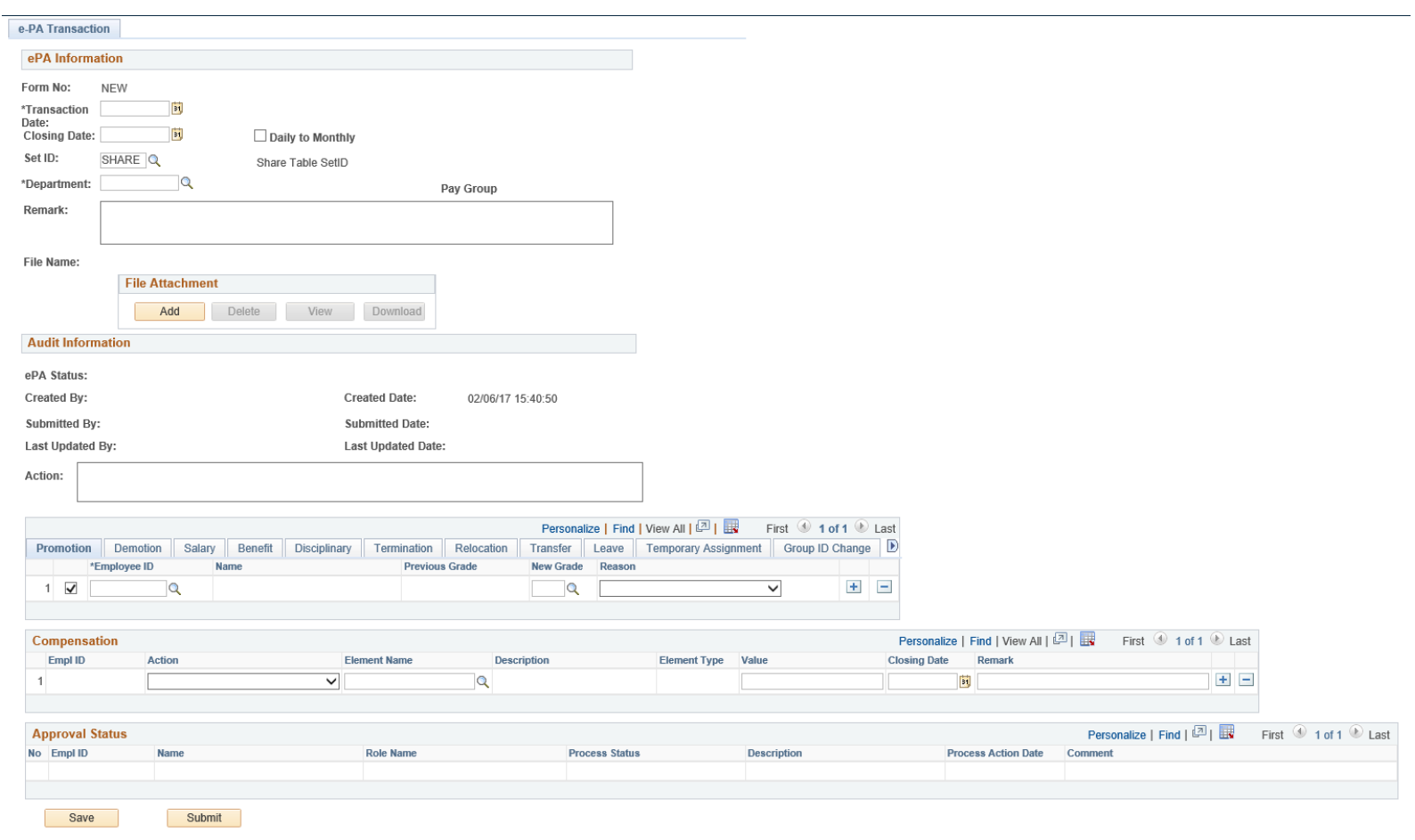

Figure 2. Display of an ePAF 
Manager is the Manager of the daily/piece-rated employee. Payroll Services is the department in charge of the payment for every employee that works for PT. $\mathrm{X}$. There are two categories of daily/piece-rated employee based on their working hours. They are: shift and non-shift workers. There are three types of verification processes. The purpose of the verification process is to reduce the possibility of human error. The importance of human error reduction is to minimize error in the system and monetary loss due to excess pay. Besides that, the employee can feel the benefit by being able to fix the error with less effort. Everything that needs to be verified is inside the ePAF. Figure 2 shows the display of an ePAF.

If an ePAF is incompatibility with a policy, it will be given a remark and then will be denied. This will be automatically sent back to the Plant Admin. A moment after an ePAF is denied, a notification will be emailed to the Plant Admin. The notification contains the reminder to Plant Admin that the ePAF they have made was denied and needs to be revised. This rejection process could be considered as wasteful because it may be a recurring problem.

\subsection{Data Processing}

Data that were used are the total denied ePAF in 2016, and then the data were categorized based on the reasons why the ePAF was denied. The categories are closing date, transaction date, supporting document, false action or remark, calculation, requested and other. Figure 3 shows the numbers of each category.

\section{Data Breakdown}
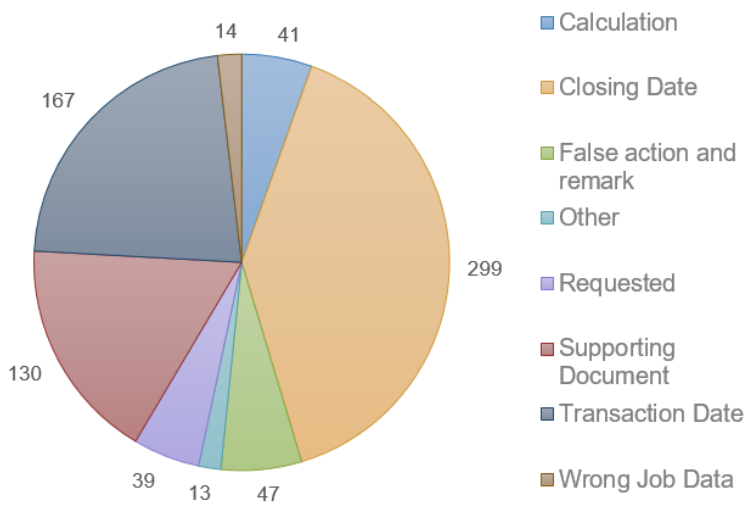

Figure 3. Reasons for ePAF rejection

Closing date error was the category with the most occurrences in 2016 with 299 cases. The result in Figure 3 shows the reasons why the ePAF was rejected. Further analysis was done using Pareto Chart that can be seen in Figure 4.

The Pareto Chart shows there are three main reasons that caused $80 \%$ of ePAF rejections. These three main reasons are closing date, transaction date, and supporting document.

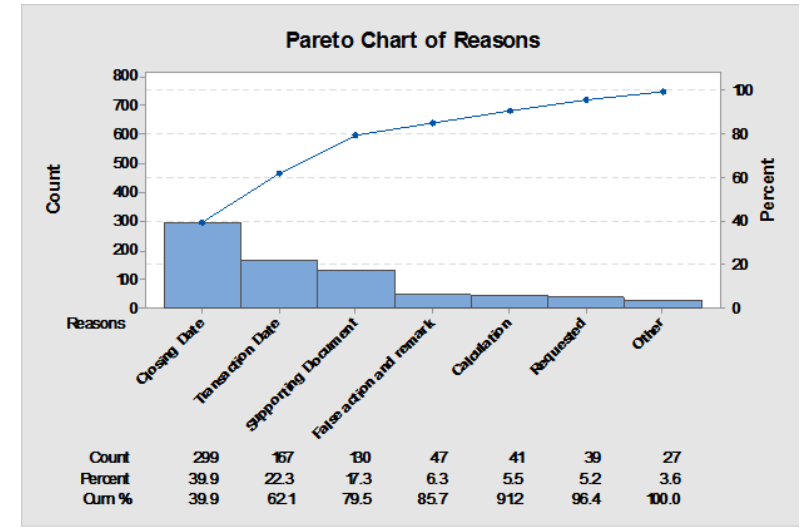

Figure 4. Pareto chart

\subsection{Problem Analysis}

The next step is to analyze the problem in the process (i.e., the reasons why the ePAF was denied) and find the root cause for each of the problems. Analysis was done using Fishbone Diagram Tools. Every problem has its own Fishbone Diagram and root cause because the problems are not related to each other. The problems or errors are analyzed based on the Pareto Chart.

\subsection{Closing Date Error}

Denied ePAF due to closing date errors are divided into two parts. These are the types of errors in closing date error:

- Closing date is incompatible with the closing date determined by Payroll Services.

- Closing date in the compensation part does not change if there are changes with the closing date column in the ePAF information part.

After a fishbone diagram is developed, the root causes for each error are found, which come from human error, method error, and system classification error. The root cause for the first type of error is that data needs to be manually input by Plant Admin. The root cause for the second error is the closing date column in the compensation part is filled in only when entering the date the first time. Therefore, any updated field in ePAF information will not automatically change the corresponding field in the compensation part.

\subsection{Transaction Date Error}

There are two kinds of problems that cause transaction date error. One is because of incompatibility between the transaction dates on the ePAF and in the supporting document. The second one is when the employee was already paid for the transaction on ePAF. The approver or verifier cannot approve the ePAF, and the ePAF will be denied. A Fishbone diagram was used and the root cause found was human error that caused the incompatibility. Another root cause can be that the system cannot assist when there is overlapping data 
Table 1. Supporting document requirements for special leave cases

\begin{tabular}{|c|c|c|}
\hline No. & Transactions & Required Documents \\
\hline 1 & Employee's own legal marriage & $\begin{array}{l}\text { Information letter from head of neighborhood group or the } \\
\text { wedding invitation, Copy ID Card }\end{array}$ \\
\hline 2 & Employee's child circumcision/baptism & $\begin{array}{l}\text { Information letter from head of neighborhood group or the } \\
\text { invitation, Copy Family Card, Copy ID Card }\end{array}$ \\
\hline 3 & Employee's child's marriage & $\begin{array}{l}\text { Information letter from head of neighborhood group or the } \\
\text { wedding invitation, Copy Family Card, Copy ID Card }\end{array}$ \\
\hline 4 & Employee's wife gives birth or miscarriage & Doctor's/Medical Certificate or Birth Certificate, Copy ID Card \\
\hline 5 & $\begin{array}{l}\text { Bereavement of spouse / parent / step-parent / parent- } \\
\text { in-law / step-parent-in-law / child / child-in-law }\end{array}$ & Obituary/Death Certificate, Copy Family Card, Copy ID Card \\
\hline 6 & $\begin{array}{l}\text { Bereavement of other family member living in the } \\
\text { same household as the employee }\end{array}$ & Obituary/Death Certificate, Copy Family Card, Copy ID Card \\
\hline 7 & $\begin{array}{l}\text { Illness of spouse or child or parent that employee } \\
\text { needs to care for }\end{array}$ & Doctor's/Medical Certificate, Copy Family Card, Copy ID Card \\
\hline 8 & Employees brother or sister's marriage & $\begin{array}{l}\text { Information letter from head of neighborhood group or the } \\
\text { wedding invitation, Copy Family Card, Copy ID Card }\end{array}$ \\
\hline 9 & Bereavement of brother, sister, brother/sister-in-law & Obituary/Death Certificate, Copy Family Card, Copy ID Card \\
\hline
\end{tabular}

within the system. Warnings that say the transaction date had already been paid only occur to Payroll Services. However, the ePAF must be denied; as it had been done, the error occurred.

\subsection{Supporting Document Error}

Problems that cause supporting document error are also divided into two parts. The first problem is incompatibility between the employee data on the supporting document with the data in ePAF. The second problem is because of a lack of supporting documents or incompatibility with the applied policies. The percentage of the first and second problems is $35 \%$ to $65 \%$ from 130 ePAFs denied because of supporting document error. Some of transactions that need a supporting document are special leave transactions. The employee needs to submit several supporting documents based on their transactions. The supporting document requirements can be seen on Table 1.

Individual leave and other transactions still need supporting documents and are written in the policies. Some Plant Admin will first check the completeness of the supporting document before making an ePAF. A fishbone diagram analysis is used to find the root cause of the problem using the same approach. There are two root causes: no standard method to publicize supporting document requirements and data needs to be manually inputted by Plant Admin. More experienced Plant Admin will first check the completeness of the supporting documents submitted by the employee and will only make an ePAF after the documents are complete. This method has proven to reduce the error caused by lack of supporting documents. There are no standard methods given by PT. X in publicizing the supporting document requirements for each transaction.

Most of the transaction errors were the special leave transactions. This is because special leave transactions are directly related to the employee. There are a lot of employees that still do not know the exact requirements for special leave, and their action is only based on experience by others or themselves from previous transactions. Many employees that are not aware of the requirements will ask the Plant Admin themselves about the requirements. This will cause an unnecessary waste of time. Other transactions that need a lot of documents are termination of an employee but the supporting documents will be prepared by Plant Admin. Plant Admin prepares the documents frequently so there is a much smaller possibility of making any mistakes.

\subsection{Improvement for Closing Date Error}

The first improvement to be discussed is to resolve the problem of incompatibility between the closing date input by Plant Admin and closing date determined by Payroll Services. The improvement is to allow the system to automatically fill in the data in the closing date column by using the nearest closing date determined by Payroll Services. This improvement is expected to eliminate human error in choosing the wrong closing date. The next improvement is to tackle the problem of closing date error, or the difference that can occur between the closing date column in ePAF information with the one in the compensation part. The improvement is to eliminate the closing date column in compensation and link the compensation part to the closing date column in ePAF information. This improvement is expected to eliminate Plant Admin error that forgets to change the closing date column in the compensation part.

The shortest time needed to revise the closing date error until Plant Admin can submit the ePAF again is 16 minutes 30 seconds. If all the improvements are implemented, then the result that PT. X can expect to see is as follows:

299 ePAF denied $\times 16.5$ minutes $=4933.5$ minutes 4933.5 minutes $\div 60=82.225$ hours

Obtained time per process includes delay time and process time. Delay time is calculated because it will impact the time it takes to receive payment of the employee's salary. 


\subsection{Improvement for Transaction Date Error}

One of the root causes that can cause transaction date error is no warning or assistance from the system when there is overlapping data. Overlapping data is when the transaction date in ePAF was already paid based on the timesheet. The improvement that has already been implemented is giving a warning when there is overlapping data between transaction date in ePAF and the data on timesheet. Every party involved, including verifier and creator of $\mathrm{ePAF}$, will receive a warning when they try to approve or submit the ePAF that has the same transaction date as on the timesheet. Leave requests that have not been past the leave date cannot be detected whether the data are overlapping or not. If the ePAF is already approved then there will be another process to fix the problem using the leave cancellation action. Leave cancellation needs to be done to cancel the leave that has already been submitted and approved. EPAF that is denied because of transaction date error is necessary to prevent PT. X from paying the employee's salary more than once.

\subsection{Improvement for Supporting Document Error}

There are two root causes that create supporting document error, and the next improvement is to tackle the lack of standard methods to publicize the supporting document requirements. The proposed improvement is to standardize the methods to publicize the supporting document requirements. One idea is making a visual media, such as a poster, to tell the employees about supporting documents required. The poster will focus on informing the employees about the supporting requirements for special leave transactions.

The next problem is the difference between the data in ePAF with the data on a supporting document caused by human error. There are no feasible improvements that can eliminate this root cause.

Average time needed to revise a denied ePAF until Plant Admin can submit the ePAF is 3 hours 28 minutes. Time reduced is expected to be:

85 ePAF denied $\times 3$ hours 4 minutes $=15,640$ minutes 15,640 minutes $\div 60=260.67$ hours

Time per process includes process time and delay time starting from when the ePAF was denied until when the ePAF was submitted again. The process starts with denying the ePAF and then coordinates with Plant Admin who makes the ePAF. After that Plant Admin will coordinate with the related employee so he or she can submit the required document(s). The employee usually needs some time to prepare the document. This problem can be amplified if the employee forgets to bring the required document. The time will vary from 1 hour to 1 day if the employee fails to bring the document or needs to get the document from another location. After an employee submits the required document, Plant Admin will proceed to scan the document and revise the ePAF before submitting it back to the first verifier.

\subsection{Determine the Implementation Priority}

The next step after proposing an improvement is to make a list of the proposed improvements and ask for the HR Services Manager's approval. The list of proposed improvements that have been approved by HR Services Manager can be seen in Table 2. There is an implementation start date in the list that was obtained using an impact effort matrix. Total time that is expected to be reduced is around 345.91 hours in one year.

Table 2. List of proposed improvements

\begin{tabular}{clc}
\hline No. & \multicolumn{1}{c}{ Improvement } & Start Time \\
\hline 1 & $\begin{array}{l}\text { Closing date column will be } \\
\text { automatically filled in by the system }\end{array}$ & After Q4 \\
\hline 2 & $\begin{array}{l}\text { Eliminate the closing date column in } \\
\text { compensation }\end{array}$ & After Q4 \\
\hline & $\begin{array}{l}\text { Make a poster consisting of supporting } \\
\text { document requirements for special leave } \\
\text { transactions }\end{array}$ & June-17 \\
\hline 4 & Making a guideline & June-17 \\
\hline
\end{tabular}

The first and second improvements can be implemented at the same time because the second improvement is related to the first one. These two improvements are system enhancements and are done by the Information Service Department which is a department outside of HR Services. The third and fourth improvements have already been implemented and the result is expected to reduce all of the number of ePAF rejected because of a lack of supporting document.

There are five categories of scale for impact and effort (see Table 3), and the bigger the number of category the bigger the impact and effort needed for the implementation of improvement. There are two aspects to be measured for effort scale. These are budget and man-days. Each aspect has its own weight. Weight is determined based on the resources that HR Services have when this proposal was given, that is, $60 \%$ for budget and $40 \%$ for man-days needed. Budget given to HR Services was very limited at the time, and man-days

Table 3. Scale used to determine the category for impact effort matrix

\begin{tabular}{|c|c|c|c|c|c|}
\hline \multirow[b]{2}{*}{ Category } & \multicolumn{4}{|c|}{ Effort } & \multirow{2}{*}{ Impact } \\
\hline & \multicolumn{3}{|c|}{ Budget } & Man-Days & \\
\hline 1 & $\operatorname{Rp} 0.00$ & - & $\operatorname{Rp} 5,000,000.00$ & 1.00 & $0 \%-10 \%$ \\
\hline 2 & Rp 5,000,001.00 & - & $\operatorname{Rp} 10,000,000.00$ & 2.00 & $11 \%-20 \%$ \\
\hline 3 & Rp $10,000,001.00$ & - & $\operatorname{Rp} 15,000,000.00$ & 3.00 & $21 \%-30 \%$ \\
\hline 4 & Rp $15,000,001.00$ & - & $\operatorname{Rp} 20,000,000.00$ & 4.00 & $31 \%-40 \%$ \\
\hline 5 & & $>$ & $\operatorname{Rp} 20,000,000.00$ & $\geq 5.00$ & $>40 \%$ \\
\hline
\end{tabular}


are more flexible. The result was done by calculating the sum of the budget, or man-days category, and multiplying by each weight (60 and 40 respectively). After that, divide it by 100 . The equation is as follows:

$(($ Budget $\times 60)+($ Man-days $\times 40)) / 100$

Therefore, with Eq. 1, the category of each impact effort matrix is found. The scale category for the impact effort matrix on every proposed improvement is shown in Table 4.

Table 4. Category scale for each improvement

\begin{tabular}{ccccc}
\hline Improve- & \multicolumn{4}{c}{ Category } \\
\cline { 2 - 5 } ment & Budget & Man-Days & Effort & Impact \\
\hline 1 & 4 & 5 & 4 & 4 \\
2 & 4 & 5 & 4 & 4 \\
3 & 1 & 4 & 2 & 2 \\
4 & 1 & 5 & 3 & 3 \\
\hline
\end{tabular}

For example, the calculation for the third improvement has a budget category at 1 and a man-days category at 4 . After we put the numbers to Eq. 1 we got 2.2 , and we round it to the nearest integer number which is 2 . This number is used as the category of effort scale. The measurements done in Table 4 are used to make the impact effort matrix shown in Figure 5.

Impact Effort Matrix

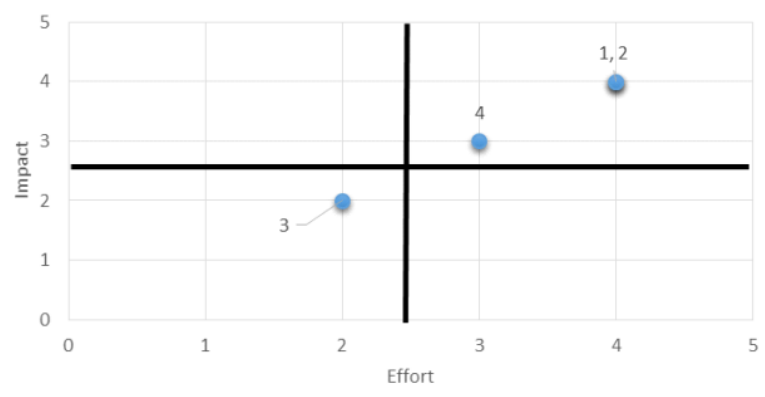

Figure 5. Impact effort matrix

Based on the rankings, the fourth improvement should be the first priority, but because the fourth improvement needs other improvements to be implemented first, the third improvement will be the first to be implemented. The first and second improvements need a large amount of budget that HR Services did not have at the time, so the first and second improvements' implementation was on hold until the fourth quarter of 2017.

\subsection{Control the Improvement}

The first control plan was made to anticipate the mistakes that can happen after the first improvement is implemented. Another system enhancement was needed in which systems can read whether the date in the transaction date column (especially on leave transactions) is bigger than the date in the closing date column. When the date in the transaction date is bigger than the date in the closing date column then a warning box will pop up that says ePAF cannot be submitted because of a wrong closing date or transaction date. The first and second improvements could cause other mistakes to occur because when Plant Admin starts to get used to the new improvement they will stop checking the closing date column because it is automatically filled in by the system. A control plan is needed to prevent this problem from happening in the future. This control plan will need to link the transaction date in the leave transactions with the date in the closing date column. A warning box will pop up when the Plant Admin tries to submit the wrong ePAF.

The next control plan was the fourth improvement that gave a guideline for the other improvements. For instance, the third improvement was implemented independently by Plant Admin so the guideline will tell us where to put the poster and ways to publicize the poster so it can be seen by the employees. Plant Admin can also ask for cooperation from employees so when the poster is not appropriate anymore, the employees can tell Plant Admin to replace it with a new one. This control plan is expected to increase awareness for everyone involved in all of the improvements.

\subsection{Knowledge Management}

There are three Admin personnel in HR Services who handle ePAF daily/piece-rated, and the knowledge they have on special cases can differ from one another. Special cases are cases with existing policies but still need judicial review regarding the policies and the conditions of the cases. HR Local is the party who makes the policies, and the HR Services Manager is the decision maker in the department. There are a lot of cases that are forgotten and not recorded or transferred during the knowledge transfer process to the new $C \& B$ Admin. This condition proves that the communication between $\mathrm{C} \& \mathrm{~B}$ Admin is not good, and that can lead to over-processing and yet more delays. If there are any special cases, C\&B Admin will ask HR Local for flexibility in the implementation of policies and ask the HR Services Manager to carry it out. Asking for the approval or action from other parties takes time to wait for a reply. This process is often not recorded by the Admin or recorded but not shared to other Admin personnel.

The improvement proposed is to provide a media to record special cases that have happened before, so when the same problem occurs again in the future, $C \& B$ Admin will only need to look at the media. This media is made using Microsoft Excel and can document every special case that every C\&B Admin has gone through. This document will be named ePAF daily/piece-rated knowledge management.

Every case in this document must have a supporting document to support the statement in the documents. These supporting documents can be anything such as response emails from the HR Local or HR Services Manager, Policies, etc. This supporting document will be useful when there is an audit to check the validity of the solution in the document. C\&B Admin can also add 
new special cases to the document. Guidelines on how to add new special cases to the document are provided in the other sheet of the document. This document should make the transfer knowledge process easier.

The document was publicized on March $1^{\text {st }}, 2017$ and has been used by all of the C\&B Admin. The improvements reduced the time wasted by $98.95 \%$ in response to special cases that had already been recorded in the document. All of $\mathrm{C} \& \mathrm{~B}$ Admin thought that the document was very useful in resolving repeated special cases and recording new special cases. Two thirds of $\mathrm{C} \& \mathrm{~B}$ Admin had already added new special cases to the document, and all of them thought that the guidelines made to add new special cases are very helpful and clear.

\section{Conclusion}

Based on data processing using Pareto Chart there were three types of errors that caused $79.5 \%$ of the total rejection processes in 2016. These were as follows: closing date error, transaction date error, and supporting document error. Closing date error was caused by two root causes - data has to be manually input by Plant Admin and unsynchronized data once it has any updated field. One proposed improvement for these root causes is to make the closing date column be automatically filled. The second proposed improvement is to eliminate the closing date column in the compensation part and merge it with the closing date column in ePAF information.

The root causes from the supporting document errors are as follows: there is no standard method to publicize the supporting document requirements and the data needs to be manually input by Plant Admin. A proposed improvement is to put a poster in every plant and give guidelines to every Plant Admin to standardize the method in every Plant.

Implementation priority from the proposed improvements is determined using the impact effort matrix. Priority is established based on the scale that considers the resources that HR Services had. All proposed improvements are expected to reduce $51.2 \%$ of ePAF denied every year, specifically with the first and second improvements, $39.9 \%$ and $11.3 \%$ respectively. Besides that, the improvements can reduce man-hour usage up to 342.92 hours per year. This number shows how much time is needed for the denied ePAF or action from each cause to be resubmitted and approved.

Another improvement was given to resolve the problem of lack in knowledge management about special cases. This improvement was to make a document of knowledge management. The knowledge management document consists of special cases that have happened before, and with this document $\mathrm{C} \& \mathrm{~B}$ Admin can solve special cases faster. This improvement succeeds in reducing the time to solve special cases around $98.95 \%$ per case that were already recorded within the knowledge management document. This data shows the time needed to process the denied ePAF until it was resubmitted.

\section{References}

1. Asefeso, A., Lean Tools, AA Global Sourcing Ltd., 2014.

2. Seth, D. and Gupta, V., Application of Value Stream Mapping for Lean Operations and Cycle Time Reduction: An Indian Case Study, Production Planning \& Control, 16(1), 2007, pp. 44-59, doi: 10.1080/09537280512331325281.

3. Bergmiller, G.G. and McCright, P.R., Parallel Models for Lean and Green Operations, Proc. of the IIE Industrial Engineering Research Conference, Miami (FL, USA), 2009.

4. Verenich, I., Dumas, M., La Rosa, M., Maggi, F.M., and Di Francescomarino, C., Minimizing Overprocessing Waste in Business Processes via Predictive Activity Ordering, Proc. of the $28^{\text {th }}$ International Conference on Advanced Information Systems Engineering, Ljubljana (Slovenia), Jun. 2016, Springer LNCS, 9694, pp. 186-202, doi: 10.1007/978-3-319-39696-5_12.

5. Montgomery, D.C., Introduction to Statistical Quality Control, $6^{\text {th }}$ ed., Jefferson City (MO, USA): John Wiley \& Sons, 2009.

6. Besterfield, D.H., Quality Control, $8^{\text {th }}$ ed., Prentice Hall, 2009.

7. Baxter, R., Operational Excellence Handbook, Naples (FA, USA): Value Generation Partners, 2015. 